\title{
O Estágio Curricular Supervisionado e o Programa Brasileiro de Iniciação à Docência: Convergências, tensões e contributos ${ }^{1}$
}

\author{
Rosenilde Nogueira Paniago $\mathrm{i}$ \\ Instituto Federal Goiano, Brasil \\ Teresa Jacinto Sarmentoii \\ Universidade do Minho, Portugal \\ Simone Albuquerque da Rochaiii \\ Universidade Federal de Mato Grosso, Brasil
}

Resumo

O texto tem origem em pesquisa que focaliza o Programa Institucional de Bolsa de Iniciação Científica a Docência (PIBID), desenvolvido no Brasil. Objetivou analisar tensões e convergências do PIBID e do Estágio Curricular Supervisionado (ECS), assim como identificar possíveis contribuições do PIBID para os Licenciandos Bolsistas do PIBID (LBP) na fase do ECS nas diferentes licenciaturas, observando-se as atividades dos coordenadores de área nesse processo. O eixo teórico que norteia este estudo é a formação de professores, no âmbito mais específico do PIBID e do ECS das Licenciaturas, tomando-se como referência teórica especialmente autores brasileiros e portugueses. Adotou-se na metodologia a abordagem qualitativa, concretizando-se em estudo de caso, apoiando-se em análise documental e entrevistas narrativas de nove LBP e três coordenadores de área dos cursos de Química, Biologia e Matemática, de um Instituto Federal de Ciências, Educação e Tecnologia. Os resultados apontaram que os LBP se destacaram no ECS, sinalizando que este programa contribui no processo reflexivo dos estagiários. Evidenciaram-se também aproximações e fragilidades entre estes dois momentos formativos no que se refere às suas finalidades, 
operacionalização e processo de supervisão, de que se ressaltam algumas tensões, resultantes, sobretudo, do perfil dos formadores, os quais nem sempre possuem formação para o exercício da função de supervisores, o que prejudica a sua ação supervisiva.

\section{Palavras-chave}

Formação Inicial de Professores; PIBID; Estágio Supervisionado

\section{Introdução}

A formação e os saberes dos professores têm ocupado lugar fulcral nas discussões, em todo o mundo, tanto por investigadores, quanto em nível das decisões políticas, diante do avanço acelerado da ciência, da tecnologia, dos meios de informação e das novas relações estabelecidas no cotidiano escolar. É um cenário que conclama novas propostas de formação inicial e continuada de professores, que contemplem as diferentes formas de ensinoaprendizagem, o trabalho com a diversidade, dentre outros aspectos.

No Brasil, após a publicação da Lei de Diretrizes e Bases da Educação Nacional n 9.394, de 20 de dezembro de 1996 (LDB/1996), como forma de incentivar a melhoria na formação de professores das Instituições de Ensino Superior (IES) e na educação básica pública brasileira, vários programas foram implementados pelo governo federal, como é o caso do Programa Institucional de Bolsa de Iniciação à Docência (PIBID), cuja ação está vinculada à Coordenação de Aperfeiçoamento de Pessoal de Nível Superior (CAPES).

O PIBID, criado em 2007, tem como foco a elevação da qualidade da formação inicial de professores por meio da inserção dos licenciandos no cotidiano da rede pública de Educação Básica, a fim de que possam vivenciar experiências metodológicas, tecnológicas e práticas de ensino inovadoras e interdisciplinares.

Assim, o presente texto resulta de uma investigação cujo objeto de estudo é a aprendizagem da docência no contexto das práticas do PIBID, de um Instituto Federal de Ciências, Educação e Tecnologia, denominado na pesquisa como IF Campo. Objetivou-se analisar tensões e convergências do 
PIBID e Estágio Curricular Supervisionado (ECS) das licenciaturas, assim como identificar as principais contribuições do PIBID para os Licenciandos Bolsistas do PIBID (LBP) na fase do estágio curricular, observando-se as atividades dos coordenadores de área nesse processo.

A instituição em que se realizou o estudo possui recente experiência na formação inicial de professores, iniciada após a exigência da Lei $n^{\circ} 11.892$ de 2008 , de se ofertar $20 \%$ de suas vagas a cursos de Licenciatura. Após essa data, o IF Campo passa a oferecer cursos de Licenciatura nas áreas de Biologia, Química, Pedagogia e Matemática, o que impõe, portanto, uma nova situação à instituição, que merece ser investigada, pois há que se ter em conta que os Institutos Federais de Ciências, Educação e Tecnologia (IF) são instituições de educação profissional, com uma história vinculada à formação técnica, que pode influenciar a formação de professores pelo viés da racionalidade técnica, cujas bases assentam no ensino profissional. Ademais, para o ingresso na docência, nos cursos de Licenciatura, não é exigida a produção no campo da educação e a experiência na educação básica, considerando que o professor atuará em vários níveis e modalidades de ensino (ensino médio técnico, Proeja, ensino superior e pós-graduação).

A motivação para este estudo decorreu da percepção de uma supervalorização na relação que os licenciandos fazem, de forma comparativa, entre as situações de aprendizagem da docência vivenciadas no PIBID e no contexto do ECS, em que exaltam em demasia o primeiro em detrimento do segundo. O que se pretende é analisar, a partir das narrativas dos LBP, as experiências vivenciadas no contexto do PIBID e do ECS. Para tanto, foram delineadas as questões: Que convergências e tensões são vivenciadas no processo de formação docente dos LBP no ECS? De que forma os coordenadores de área acompanham o processo formativo dos LBP para a aprendizagem da docência? Quais as contribuições do PIBID para os LBP que se encontram na fase de ECS?

\section{O ECS e o PIBID no contexto de formação inicial de professores no Brasil}

As atuais múltiplas exigências do processo ensino-aprendizagem tornam a docência uma profissão cada dia mais complexa, desafiando os 
diversos sistemas educativos, o que se repercute nas reformas introduzidas na formação inicial de professores.

Nas últimas duas décadas, o governo brasileiro desencadeou várias iniciativas acerca da formação para a docência, no âmbito do Ministério de Educação e do Conselho Nacional de Educação (CNE). Vários programas e leis foram implementados, tais como o PIBID e as Diretrizes Curriculares Nacionais (DCN), para todos os cursos de graduação do país, focalizando, entre outros aspectos, o ECS.

Com a aprovação da LDB/1996, o CNE ficou responsável pela definição das DCN. Nesse sentido, na Resolução CNE n¹/2002, de 18 de fevereiro, foi instituída a DCN/2002 e, na Resolução CNE n²/2002, de 19 de fevereiro, ficou estabelecida a carga horária mínima de 400 horas para o ECS, com início a partir do início da segunda metade do curso. Na atual Resolução CNE $n^{\circ} 2 / 2015$, de 1 de julho, que define as DCN/2015 para a formação inicial e continuada, é mantida essa mesma carga horária e afirmado que o ECS deve ser uma atividade articulada com a prática e com as demais atividades dos cursos de Licenciatura. O ECS é um componente curricular obrigatório em todas as Licenciaturas e deve se iniciar a partir da metade do curso, como forma de garantir a inserção dos formandos no cotidiano da escola para a aprendizagem da docência.

No que se refere ao PIBID, este programa, que foi criado pelo Decreto $n^{\circ} 7.219 / 2010$, tem-se destacado pelo crescente número de IES e bolsistas dele participantes. O programa iniciou as atividades priorizando os cursos de Licenciatura nas áreas de Física, Química, Biologia e Matemática, para o Ensino Médio, mediante a carência de professores para atuarem nessas disciplinas. Participaram na primeira versão apenas as Instituições Federais de Ensino Superior, com 3088 bolsistas (alunos das Licenciaturas, professores das IES e professores das escolas de educação básica). A partir dos bons resultados da primeira versão, de 2010 a 2013, foram lançados outros editais e selecionadas outras IES, de modo que, no final de 2014 , participavam do programa 284 IES, oferecendo 313 projetos de iniciação à docência a mais de 90 mil bolsistas.

Neste programa, os alunos das Licenciaturas, sob a supervisão de professores das IES e da escola de educação básica, podem participar, nas escolas públicas, a partir do início de sua formação, de experiências de 
aprendizagem da docência que perpassam desde o conhecimento de questões administrativas, de gestão, questões socioculturais dos alunos, relações interpessoais, até práticas de ensino em sala de aula.

Todos os integrantes do PIBID, como estímulo à sua participação, recebem bolsas que, em poucos anos, tiveram um vertiginoso aumento, o que, somado aos seus bons resultados formativos e à aprovação da Lei $n^{\circ}$ 12.796, de 12 de abril de 2013, obrigou a alterar o texto da LDB/1996 para incluí-lo. Tal inserção desencadeou um sentimento generalizado, no país, de que ele se consolidaria como política de Estado, não sujeita a descontinuidade com a mudança de governo. Inclusive, a própria CAPES afirma que a proposta é a de que "o PIBID, a exemplo do Programa Institucional de Bolsa de Iniciação Científica - PIBIC, que valorizou a ciência nas universidades, seja uma política de Estado voltada para formação de professores" (Relatório DEB/CAPES, 2013, p. 68). Todavia, a grave crise política e econômica que assolou o país tem afetado o PIBID em demasia, colocando em dúvida a sua continuidade. As mobilizações em prol de sua permanência têm sido imensas, tendo como principal representação o Fórum Nacional dos Coordenadores do PIBID (FORBID), conquanto não se saiba ainda quais os rumos que ele tomará.

Gatti, André, Gimenes, e Ferragut (2014) realçam que o PIBID contribui "para a valorização da profissão de professor. Constitui-se em rara política de atenção à formação inicial dos professores para a educação básica. É um programa que desacomoda as licenciaturas e mobiliza escolas" (p. 106). E prosseguem afirmando que, diante de suas contribuições, ele deve ser institucionalizado e se tornar perene como política de Estado, ideia também defendida pelas pesquisadoras do presente estudo. Por sua vez, Nascimento, Almeida, e Passos (2016) apontam que o PIBID apresenta possibilidades formativas com elevado potencial, tendo em vista que promove o diálogo entre a formação inicial e o trabalho docente, enseja a aprendizagem da docência suportada na partilha da reflexão e da crítica sobre as práticas, beneficia as IES e as escolas de educação básica implicando reciprocidade na responsabilidade formativa.

Apesar das várias decisões políticas e mudanças nos processos formativos das IES, os programas de formação não têm respondido adequadamente às exigências formativas atuais, não atendem ao movimento 
social em constante transformação, estão distantes da realidade organizacional da escola e dos conhecimentos práticos dos professores (Gatti \& Barreto, 2009). As autoras, além de destacarem que nas IES ocorre a ausência de um perfil profissional claro de professor, afirmam que os currículos não se articulam com a prática profissional, "seus fundamentos metodológicos e formas de trabalhar em sala de aula. Continuam a privilegiar preponderantemente os conhecimentos da área disciplinar em detrimento dos conhecimentos pedagógicos propriamente ditos" (Gatti \& Barreto, 2009, p. 258).

Os processos formativos muitas vezes estão associados a uma abordagem tecnológica na perspectiva da racionalidade técnica, em que a prática fica situada no final do currículo, após a formação na base de conhecimento teórico-científico. Uma formação de professores assente numa racionalidade técnica apoia-se, segundo a visão crítica de Gómez (1997), em três pressupostos: primeiro, a investigação acadêmica produz os conhecimentos necessários aos professores do ensino fundamental; segundo, o conhecimento acadêmico prepara os professores para situações problemáticas de sala de aula; terceiro, a ligação hierárquica e linear entre a produção do conhecimento científico e sua aplicação prática induz a uma perceção de que também há uma relação linear entre o ensino e a aprendizagem. Neste modelo formativo há uma distância entre quem produz o conhecimento (os acadêmicos, considerados profissionais) e quem aplica o conhecimento (os professores da escola fundamental, considerados proletários).

Por certo, um modelo formativo consubstanciado nos princípios da racionalidade técnica não mais serve para o momento atual, em que os avanços conclamam outro profissional, que mobilize vários saberes para enfrentar as diferentes situações do cotidiano escolar. Urge, pois, a necessidade de se apostar em tendências formativas que focalizam o desenvolvimento profissional dos professores como profissionais reflexivos, investigativos, com capacidade de decisão em face das diferentes problemáticas, singulares, ambíguas, incertas, da sala de aula, contextos escolares e não escolares.

Assim se faz importante perspectivar a formação inicial de professores que incite ao diálogo com as práticas da educação básica, oportunizando ao 
formando a aproximação com a escola suportada na investigação. Para Alarcão e Roldão (2008), a supervisão deve preparar os formandos para a atuação em situações complexas de forma a desenvolverem "a observação crítica; a problematização e a pesquisa; o diálogo; a experienciação de diferentes papéis; o relacionamento plural e multifacetado; o autoconhecimento relativo a saberes e práticas" (p. 54).

\section{O estágio como um momento-chave de inserção na socialização profissional}

O estágio constitui-se em um momento-chave na formação profissional, no qual o futuro professor se confronta com a realidade da sua ação profissional, presente ou futura, permitindo-lhe uma socialização/interação com os seus principais referentes - os alunos, as matérias científicas a lecionar, os tempos a gerir, os espaços e materiais que selecionará e organizará. Defende-se o estágio, enquanto práxis educativa, não como um campo de aplicação de um saber teórico, mas sim como um espaço de produção de conhecimento autônomo, construído com a mobilização de saberes teóricos e articulados com um conjunto de competências atitudinais e investigativas, numa simbiose entre o saber, o fazer e o ser.

O estágio será, assim, uma oportunidade de articulação entre práticateoria, o que, para ser bem estruturado, necessita de apoios vários, de que se realça um bom suporte teórico e a mediação a ser feita pelos professores supervisores. Alguns autores, entre eles Pimenta e Lima (2011), Roldão (2001), Canário (2001), Zeichner (2010), Vieira et al. (2013), têm-se debruçado sobre as estratégias de formação, com vistas à promoção do desenvolvimento crítico da ação docente, conducente ao desenvolvimento profissional, realçando as vantagens da formação no contexto, logo, a formação assente na prática profissional.

Roldão (2001) aconselha que os futuros professores se apetrechem com saberes de referência sólidos no plano científico-profissional, estruturantes e mapeadores do campo do conhecimento profissional; com competências para ensinar, emergentes e integradoras do saber profissional, contextualizadas na ação docente; com competências de produção articulada 
com conhecimento profissional gerado na ação e na reflexão sobre a ação, teorizado, questionante e questionável, comunicável e apropriável pela comunidade de profissionais.

Canário (2001), dentro da mesma linha de pensamento, chama a atenção para o valor epistemológico da experiência na formação de professores, defendendo que "o mais importante na formação inicial consiste em aprender a aprender com a experiência" (p. 32), o que implica uma relação estratégica entre a formação e o trabalho (iniciada na relação das diferentes unidades curriculares teóricas com as práticas pedagógicas, ainda na formação inicial), de forma a possibilitar o saber mobilizar os conhecimentos para as situações específicas que vão ocorrendo.

Por sua vez, Zeichner (2010), ao defender a necessidade de diálogo entre as IES e as escolas de educação básica, sugere a criação de espaços híbridos que "reúnem professores da Educação Básica e do Ensino Superior, e conhecimento prático profissional e acadêmico em novas formas para aprimorar a aprendizagem dos futuros professores" (p. 487). Estes espaços traduzem uma relação mais dialética e equilibrada entre os conhecimentos acadêmicos e práticos da docência.

Realça-se que a compreensão de estágio aqui abordada não se atém à posição dicotômica da teoria e prática, em que o estágio compreende um processo isolado e individual do estagiário, um período de prática, consubstanciada em atividade pontual, na escola de educação básica, ao como fazer em sala de aula, às técnicas a serem empregadas, entre outras atividades mecânicas e tecnicistas. Ao contrário do apresentado, defende-se que o ECS se efetive como um processo que "envolve todas as disciplinas do curso de formação constituindo um verdadeiro e articulado projeto políticopedagógico de formação de professores cuja marca é alavancar o estágio como pesquisa" (Pimenta \& Lima, 2011, p. 56).

Vislumbra-se o ECS como um processo traduzido por espaços e tempos de aproximação com a realidade educativa, com finalidade definida, como processo problematizador, reflexivo, em que ocorre a formação na e pela pesquisa, pois "o estágio é atividade teórica de conhecimento, fundamentação, diálogo e intervenção na realidade. Ou seja, é no contexto da sala de aula, da escola, do sistema de ensino e da sociedade que a práxis se dá" (Pimenta \& Lima, 2011, p. 45). 
A reflexão, como elemento imprescindível na formação, consiste em processo significativo que influencia nas atividades práticas que ocorrem no cotidiano da sala de aula; no entanto, na corrente formativa em que se situa a presente discussão, esse saber, por si só, não é suficiente para se constituir em saber profissional. Reforça-se a importância da inclusão da pesquisa, da investigação, da mobilização dos conhecimentos prévios, mediada - durante a formação inicial - pelos professores do ensino superior, de forma a garantir uma sustentabilidade teórica que ajude a encontrar novas formas de dar uma resposta qualificada ao devir educativo.

A perspectiva formativa aqui defendida se aproxima da proposta por Vieira et al. (2013) ao apresentarem um projeto de intervenção pedagógica no ECS, articulando investigação e ensino, em que um dos princípios é a investigação ao serviço da pedagogia, cuja finalidade é produzir conhecimento que auxilie a melhor compreender o processo de ensinoaprendizagem e a aprendizagem na área da docência. Afinal, conforme diz Flávia Vieira (2015), "[a] investigação pedagógica é uma investigação que incide sobre a pedagogia e que nos ensina algo de útil sobre como promover uma educação mais democrática nas escolas".

\section{Percurso Metodológico}

A pesquisa baseou-se na abordagem qualitativa, concretizando-se num estudo de caso, adotando como procedimento de coleta a análise documental e as entrevistas narrativas. Em termos de análise documental, analisou-se a legislação oficial sobre o PIBID, os subprojetos de áreas, o projeto e o relatório institucional da IES apresentado à CAPES.

Recolheram-se narrativas de nove Licenciandos Bolsistas do PIBID (LBP) das licenciaturas de Química, Biologia e Matemática, e de três professores da IES, coordenadores dos subprojetos de área (CA) dos quais os bolsistas participam. Especificamente, neste texto, ampliam-se as informações coletadas com os LBP, inserindo-se ainda os testemunhos dos $C A$. Do ponto de vista da identificação, os CA serão assim descritos: CEM de Matemática; CLQ de Química; e CGB de Biologia. Os LBP serão identificados com palavras que representam alguma das características observadas em sua postura, durante a recolha das entrevistas narrativas, assim sendo: 


\begin{tabular}{|l|l|}
\hline Biologia & Alvorecer, Lua e Vida \\
\hline Matemática & Iluminado, Bela e Coragem \\
\hline Química & Força, Esperança e Paz \\
\hline
\end{tabular}

A construção das narrativas esteve referenciada em autores como Sarmento (2002), Clandinin e Connelly (2011), dentre outros. Sobre as narrativas, Clandinin e Connelly (2011) justificam que

los seres humanos somos organismos contadores de historias, organismos que, individual y socialmente, vivimos vidas relatadas. El estudio de la narrativa, por lo tanto, es el estudio de la forma en que los seres humanos experimentamos o mundo. De esta idea general se deriva la tesis de que la educación es la construcción y la reconstrucción de historias personales y sociales. (pp. 11-12)

Os dados foram organizados e analisados com suporte em Bardin (2013), tendo como norte as três diferentes fases de análise de conteúdo: 1) a pré-análise; 2) a exploração do material e o tratamento dos dados; 3) a inferência e a interpretação. Dentre as categorias trabalhadas na pesquisa selecionou-se uma delas, "O estágio e o PIBID: convergências, tensões e contributos", com três subcategorias a seguir descritas para as análises: a) Convergências e tensões do ECS e do PIBID em aspectos gerais; b) Aproximações e fragilidades do ECS e do PIBID no processo de supervisão; c) Contribuições do PIBID para o ECS.

\section{Convergências e tensões do ECS e do PIBID em aspectos gerais}

De modo geral, é possível evidenciar muitas convergências entre o ECS e o PIBID, principalmente na forma de operacionalização e quanto às suas finalidades. No que se refere às finalidades, a inserção dos formandos no cotidiano da escola de educação básica é um dos pontos semelhantes, conforme narram os LBP:

O estágio e o PIBID têm o mesmo objetivo, que é levar o aluno da Licenciatura para o contexto escolar ... são espaços de troca de conhecimentos e de aprendizado, pois proporcionam uma maior visão do contexto escolar, por meio da atuação em sala de aula e do contato com os demais membros da escola. (Bela, 16 maio 2014) 
O PIBID e o estágio nos aproximam da escola, mostrando a realidade da educação, mostra as dificuldades enfrentadas pelo professor, o dia a dia dos professores. (Alvorecer, 25 junho 2014)

O PIBID e o estágio possuem semelhanças, pois nos permitem conhecer a realidade das escolas e também relacionar a teoria estudada com a prática em sala de aula. (Paz, 17 maio 2014)

É reconhecido pelos LBP que o PIBID e o ECS ensejam o contato com a realidade da educação básica, o que permite afirmar que são momentos significativos para a socialização docente, compreendida como processo, as dinâmicas relacionais e as estratégias de aprendizagem vivenciadas pelos formandos no cotidiano da escola, pelos quais vão adquirir alguns dos saberes da docência. Daí, observa-se, pelos excertos de falas, que os licenciandos evidenciam e valorizam a escola como espaço formativo. Canário (2001) corrobora esta reflexão ao realçar o valor da experiência para a aprendizagem docente na formação.

Por certo, o ECS tem como objetivo o desenvolvimento de saberes da docência, por meio da articulação teoria-prática e vivência de situações do trabalho docente. Tal como já constatamos, o ECS é espaço significante na formação por ensejar aos formandos "estabelecer a relação teoria-prática, conviver com a complexidade do cotidiano escolar e, sobretudo, experienciar práticas de interação educativa com os alunos" (Paniago \& Sarmento, 2015, p. 77).

Da mesma forma, na atual Portaria $n^{\circ}$ 096/2013, que normatiza o PIBID, fica esclarecido que um dos objetivos do programa é a inserção dos formandos em seu futuro campo de trabalho, para que se "insiram na cultura escolar do magistério, por meio da apropriação e da reflexão sobre instrumentos, saberes e peculiaridades do trabalho docente" (p. 3). A inserção, a relação teoria-prática para a vivência do trabalho docente na formação são, pois, aspectos nos quais convergem esses dois momentos formativos. Sobre eles se pronuncia CEM: "Sou suspeita para falar do PIBID, pois enquanto coordenadora de área do curso de Licenciatura em Matemática, vejo-o como um programa ímpar . . . acredito que o PIBID é uma extensão do estágio" (22 maio 2014). Depreende-se que a CEM considera o PIBID um processo semelhante ao ECS, a tal ponto que o compara a uma extensão do último. 
Do ponto de vista da operacionalização, destaca-se que o ECS e o PIBID são espaços fecundos para o trabalho com a investigação na formação, por oportunizarem a análise de problemáticas do cotidiano escolar e da sala de aula, ações de intervenção por meio de projetos, em uma perspectiva coletiva e interdisciplinar, sistematização reflexiva das ações, dentre outras. Por conseguinte, ocorre a efetiva articulação do tripé - ensino, pesquisa e extensão -, tão necessária às reais finalidades das IES. Com essa reflexão corroboram Pimenta e Lima (2011), ao defenderem a necessidade e a importância da inserção da pesquisa no estágio, que se deve basear em uma "atitude investigativa, que envolve a reflexão e a intervenção na vida da escola, dos professores, dos alunos e da sociedade" (p. 34).

Apesar de haver vários elementos convergentes entre o ECS e o PIBID, é possível identificar também tensões e dilemas, traduzidos pelo oferecimento de bolsas aos LBP e tempo de inserção no cotidiano da escola para a aprendizagem da docência.

Conforme já afirmado, o ECS é um componente curricular obrigatório a todos os alunos de cursos de Licenciatura. Já do PIBID participam apenas alguns alunos selecionados na IES, os quais são privilegiados em relação aos demais, pois ao participarem recebem bolsas. Assim, o apoio financeiro se coloca como um aspecto de tensão entre o ECS e o PIBID, já que todos os participantes do PIBID (professores da escola de educação básica, da IES e LBP) recebem bolsas e apoio financeiro para participarem de eventos científicos e realizarem projetos na escola, o que incita a realização de práticas diferenciadas no contexto escolar, com supervisão mais ativa e motivada.

Já os estagiários dos cursos de Licenciatura, os orientadores de estágio e o professor que atua com os estagiários nas escolas não recebem apoio financeiro; ocorre apenas uma parceria entre a IES e a escola, com vistas ao desenvolvimento do estágio. Por conseguinte, os alunos que não fazem parte do PIBID encontram dificuldades para a sua realização, para o que concorrem vários fatores: muitos trabalham, o que dificulta o horário para a realização das atividades; os professores supervisores da escola de educação básica nem sempre possuem espaço e interesse para recebê-los; os professores da IES nem sempre possuem tempo e interesse para se dedicarem às atividades de supervisão, conforme afirma CGB: "temos 
problemas com o estágio, pois muitos professores não se interessam em orientar os alunos, preferem se dedicar a outras atividades, como a pesquisa em suas áreas, e ao PIBID" (19 agosto 2014). Por sua vez, CEM afirma que

No estágio, os professores supervisores não estão muito interessados em acompanhar os discentes, por vezes os deixam em sala de aula sem apoio. No PIBID, acho que a bolsa os incentiva a se dedicar. Também vejo que os colegas que atuam nos cursos de formação que são do PIBID são mais dedicados, acompanham mais do que os que apenas orientam o estágio. (20 agosto 2014)

Por certo, a bolsa do PIBID motiva a participação dos professores no programa, enquanto no ECS as atividades de orientação não são muito bem vistas pelos professores da IES, que não estão muito dispostos a orientar os alunos, preferindo se dedicar a outras atividades mais reconhecidas, como a orientação de alunos de iniciação científica, atividades de pós-graduação, dentre outras.

Outro aspecto que traduz uma relação de tensão e ambiguidade entre os dois momentos formativos no IF Campo refere-se ao tempo de vivência no cotidiano da escola de educação básica, tendo em vista que, no PIBID, os LBP podem ingressar desde o início do curso. Acerca da experiência nos dois momentos formativos, um bolsista do PIBID assim se pronuncia:

No estágio são 400 horas divididas em dois anos; no PIBID não! Eu fiquei dois anos e meio no PIBID; então é um tempo bastante grande. Se você for contabilizar as horas que você fica na escola, o estágio fica bem atrás em questão de horas. Então você consegue, com o PIBID, ter mais ações numa escola, conhecer essa escola de fato. . . . No estágio você fica mais assistindo aula . . . não é uma parte real da vida do professor, porque vai lá e aplica uma aula diferente e os alunos gostam; no PIBID não, você mescla os dois, tem aula, tem aula diferente, e vê como é a rotina de um professor. (lluminado, 20 agosto 2014)

É possível inferir que o tempo que os LPB permanecem na escola, no PIBID, enseja a participação em situações reais no exercício da docência, o que se diferencia do estágio, por se constituir momento pontual que, muitas vezes, não permite ao formando experimentar as ambiguidades da escola e da sala de aula. A esse respeito também se pronunciam os coordenadores de Área (CA):

No PIBID trabalha-se com mais tempo e, consequentemente, se discute mais os referenciais teóricos . . . a parte de aprofundar as questões de organização da escola, eles não aprofundam não, no estágio o tempo é muito curto. (CLQ, 25 junho 2014) 
O estágio, ele é muito quadradinho; eu tenho tantas horas para observar, tantas horas para fazer isto e aquilo. O PIBID é mais flexível, está sempre atuando em alguma questão; por exemplo, na etapa do diagnóstico, ele dá mais liberdade para o aluno trabalhar; ele pode fazer várias coisas e o estágio não, é só aquilo ali. Muitas vezes o aluno quer saber apenas o que tem que cumprir; são 10 horas de observação de aula, então é isso que vou cumprir. Nós temos tantas horas do estágio destinado à elaboração de um projeto educativo, mas, muitas vezes, faz aquilo só para cumprir tabela, e muitas coisas no estágio a escola não deixa eles vivenciarem. (CGB, 19 agosto 2014)

Os CA reafirmam que, no PIBID, os formandos podem ficar um tempo mais alargado na escola, o que possibilita a realização de atividades que não são possíveis no ECS. Não obstante, os CA destacam a flexibilidade e a autonomia, no que se refere ao tempo e à escolha das atividades a serem realizadas no PIBID, o que, por certo, segundo eles, não ocorre no ECS, pois já são predefinidas. Também é sinalizado, por CGB, que o estágio do IF Campo é consubstanciado em ações pontuais, quando os estagiários, a partir do $5^{\circ}$ período do curso, se deslocam para a escola com a finalidade de cumprirem a carga horária e preencherem as fichas e documentos destinados para tal fim, fato também sinalizado em uma das narrativas:

Achei o estágio superficial, como uma receita; você tem que chegar na escola, analisar sua parte física, o PPP, os planos, depois se observa a aula de um professor. . . . O PIBID consegue dar mais liberdade ao aluno, para que possa criar a sua identidade como professor. . . é bem mais amplo; não tem receita, não tem ações preestabelecidas, para se realizar na escola. Essas ações são construídas a partir de um projeto estruturado junto com o orientador, com o coordenador e alunos bolsistas. Então são várias visões, vários olhares sobre um determinado ponto. (lluminado, 20 agosto 2014)

Conforme se observa, o LBP revela a sua percepção sobre as divergências nos dois momentos formativos, sinalizando a fragilidade do primeiro, como espaço de aprendizagem da docência, em relação ao segundo. Para ele, no PIBID é proporcionada autonomia para os formandos no tocante à construção das ações a serem desenvolvidas, enquanto que no ECS elas se atêm ao cumprimento de ações de acordo com a carga horária estabelecida. Colaboram aqui Gatti e Barreto (2009) ao afirmarem que os estágios mostram-se fragilizados, "constam nas propostas curriculares sem planejamento e sem vinculação clara com os sistemas escolares, e sem explicitar as formas de sua supervisão" (p. 258). Também os CA se manifestam a respeito: 
O PIBID é diversificado ... temos um cronograma nosso, é mais aberto, sabe? A gente pode fazer várias coisas e ver se dá certo. Temos um cronograma, mas podemos mudar a rota, sabe? (CGB, 19 agosto 2014)

No PIBID os alunos têm a oportunidade de conhecer a realidade escolar, diagnosticar os problemas da escola e atuar ativamente e conjuntamente com a mesma, planejando e propondo ações de intervenção no contexto da sala de aula e fora dela. Enquanto o estágio limita à sala de aula, o PIBID permite ao futuro professor conhecer os outros ambientes da escola, as reuniões de classe, outros programas desenvolvidos, o projeto político pedagógico, etc. (CEM, 22 maio 2014)

As narrativas dos LPB e dos CA permitem afirmar que as intencionalidades do PIBID estão sendo concretizadas no processo formativo de professores das IES, em referência à sua importância para a aprendizagem da docência quanto às possibilidades da vivência de diversas atividades que transcendem a sala de aula e possibilitam a operacionalização de um processo consubstanciado na ação, reflexão e ação, conforme afirma CEM. As práticas do programa ensejam aos LBP conhecerem e assumirem funções em aspectos da organização da escola, para além da sala de aula e, com isso, poderem alargar o seu sentido crítico sobre as ideologias que estão subjacentes a determinadas formas de organização: como é que a escola assume o seu compromisso social, como combate ou não as desigualdades de oportunidades e de justiça, entre outras. Um dos CA narra as contribuições do programa:

os alunos do PIBID desenvolvem a criticidade sobre os vários eixos da educação, seja por exemplo na parte de como ensinar, o que ensinar, seja na parte de conhecer a organização da escola e o seu papel, seja na parte da escrita, seja na parte política e administrativa da escola. Então, não ficam alienados. (CLQ, 21 agosto 2014)

Entretanto, ocorrem disparidades e tensões no processo formativo das Licenciaturas, pois a forma como o estágio vem sendo desenvolvido, em que não ocorre uma relação orgânica, processual, entre os conhecimentos estudados no curso e as práticas de estágio, prejudica os demais alunos que não possuem a oportunidade de participar do PIBID. Inclusive, a própria CAPES reconhece tal situação, ao pronunciar que "A inserção no cotidiano das escolas deve ser orgânica e não de caráter de observação, como muitas vezes acontece no estágio. A vivência de múltiplos aspectos pedagógicos das escolas é essencial ao bolsista" (Relatório DEB/CAPES, 2013, p. 68). 
Ademais, também já foi constatado, em texto anterior (Paniago \& Sarmento, 2015), que há outros elementos emblemáticos pertinentes ao ECS do IF Campo em que ocorre

uma disjunção entre a prática efetiva de estágio e as orientações da IES, fato que permite afirmar a ocorrência de fragmentação, de descontinuidade entre os conhecimentos teórico-conceituais das disciplinas e a prática de estágio, bem como a ausência de planejamento, de reflexões coletivas por parte dos formadores que atuam no estágio, de modo a possibilitar orientações comuns e melhor apoio aos estagiários. (p. 94)

Dessa forma, a relação teoria-prática ocorre, geralmente, apenas no ECS, e consubstanciada em relações pontuais desprovidas de práxis, o que permite inferir que os alunos que fazem parte do PIBID são privilegiados na concretização da relação teoria-prática, tendo em vista que a eles são oportunizadas diversas vivências de socialização à docência desde o início da formação, com melhor acompanhamento por parte dos supervisores. A esse respeito, Vieira $(2015)^{2}$ aponta a sua percepção em relação à tensão existente entre o PIBID e o ECS, ao falar que "na altura em que estive na vossa instituição, . . . ficou muito visível nas apresentações a que assisti, inclusive, a de um aluno que elogiava o PIBID, estava muito satisfeito com o trabalho, e, pelo contrário, criticava o estágio curricular". Então, para a autora, o grande desafio é articular esses dois momentos formativos:

Caso contrário, correm-se riscos, do meu ponto de vista, sérios, que é estar a criar uma alternativa ao estágio que nem todos podem frequentar e, portanto, estar a criar aí desigualdades que podem ser mal interpretadas, e com alguma razão, se calhar, pelos próprios estudantes e também pelos próprios supervisores. (Vieira, 2015)

Por certo, as intencionalidades do PIBID estão sendo concretizadas no processo formativo de professores das IES. Entretanto, há que se ter em conta que aos demais licenciandos também deve ser dada a oportunidade da vivência orgânica dos aspectos multifacetados da escola e da sala de aula.

Outro aspecto que apresenta algumas convergências e fragilidades, no âmbito do ECS e do PIBID, atribui-se à supervisão pedagógica, discussão apresentada a seguir.

\section{Aproximações e fragilidades do ECS e do PIBID no processo de supervisão}

Das convergências do processo de supervisão do ECS e do PIBID, destacar-se-á a forma de orientação e as aprendizagens dos participantes; 
como fragilidades serão sinalizados o tempo e a ausência de formação pedagógica dos formadores do IF Campo.

Entende-se que o ECS, tal como o PIBID, pressupõe ações pedagógicas supervisionadas de aprendizagem da docência, operacionalizadas em ambientes institucionais, futuro campo de trabalho dos formandos, com vista a concretizarem a relação teoria-prática na construção dos saberes da docência. Compreende-se aqui a supervisão na acepção de Alarcão e Tavares (2003), "como o processo em que um professor, em princípio mais experiente e mais informado, orienta outro professor ou candidato a professor no seu desenvolvimento profissional" (p. 16). Realça-se ainda que a supervisão, no contexto da formação inicial, envolve também o processo de aprendizagem do licenciando que supervisiona a própria aprendizagem.

No caso específico desta discussão, a palavra "supervisionado" traduz o processo de orientação realizado por profissionais da educação básica e da IES aos licenciandos, o que pressupõe que a supervisão seja feita por professores mais experientes e com formação acerca dos saberes que irão mediar, que assegurem uma orientação coerente com os propósitos da supervisão que aqui se defende, qual seja, a formação de professores com capacidade de, por meio da pesquisa, problematizar as desafiantes questões emergentes no cotidiano escolar e de sala de aula, refletindo sobre elas e nelas intervindo.

No PIBID, tais professores são designados de supervisores e coordenadores de área; já no processo de ECS do IF Campo, são nomeados supervisores e orientadores. Aqui, serão tratados como professores supervisores, sendo que o professor da educação básica que recebe o licenciando será intitulado de coformador, e o professor da IES formador. No processo de supervisão, seja do PIBID ou do ECS, os supervisores ocupam um papel primordial; por conseguinte, o não exercício de sua função produz significativo prejuízo para a aprendizagem dos formandos.

A supervisão realiza-se numa tríade (professor da IES - professor da escola de educação básica - estagiário), ou numa díade (professor da IES estagiário). O foco é a formação do estagiário, verificando-se também que os demais integrantes são sujeitos a um processo de formação, participando dele colaborativamente. De forma análoga, o ECS e o PIBID, além de 
contribuírem para a formação dos licenciados, incitam a formação continuada dos coformadores e formadores, por meio da partilha de saberes e experiências. Dessa forma, os dois cenários formativos - ECS e PIBID - e todos os participantes (formador, coformador e formandos) são beneficiados. Segundo a CAPES, "a rede de colaboradores que se forma a partir do PIBID possibilita que não apenas as concepções dos alunos das Licenciaturas sejam afetadas, mas igualmente sejam tensionados os paradigmas dos formadores (professores da educação básica e das IES)" (Relatório DEB/CAPES, 2013, p. 70).

Por certo, existem outras convergências entre esses dois espaços formativos; contudo, não será possível aprofundá-las, no momento - o que será feito em futuras investigações -, pelo que, já, serão apresentadas as fragilidades, aqui traduzidas pela ausência de diálogo entre os supervisores (formador e coformador), bem como pelo tempo e ausência de formação pedagógica dos formadores.

Constatou-se que, no processo de supervisão do ECS e do PIBID do IF Campo, ocorre um distanciamento na orientação realizada pelos supervisores, conforme afirma um LBP: "o professor supervisor apenas repassava o tema da aula, que o mesmo gostaria de alguma intervenção diferenciada, e nós, bolsistas, juntamente com o professor orientador, elaborávamos tais planos de aula" (Força, 14 de maio 2014). Na mesma direção, afirma outra LBP: "a gente não participou de planejamento com ela . . . a gente pegou o plano de aula dela e observou como ela realizava esses planos de aula" (Esperança, 15 maio 2014 ). Outro LBP aponta que:

tivemos duas supervisoras na área de matemática, só que uma delas, em dois anos e meio que a gente teve de PIBID, se encontrei com ela duas vezes foi muito; ela era muito ausente do programa, muito, muito ausente. Ela ficava mesmo atrás das cortinas, ela quase nunca apareceu mesmo. (lluminado, 20 agosto 2014)

As narrativas dos LBP sinalizam, portanto, que não houve momentos colaborativos entre a equipe do PIBID, para que pudessem elaborar planejamentos e fazer as intervenções em sala de aula. Também no ECS a situação ocorre, tal como dito em texto anterior: "A falta de articulação entre a teoria-prática do estágio . . . somada à ausência de planejamento e reflexão coletiva entre os professores formadores da IES e destes com os titulares de 
turma da educação básica, traduz um processo formativo baseado na racionalidade técnica" (Paniago \& Sarmento, 2015, p. 94).

Soma-se, a esse quadro, a disjunção que ocorre entre a IES, as escolas de educação básica e os profissionais que atuam nesse nível de ensino, durante o processo de ECS, que, muitas vezes, desconhecem o que acontece no âmbito de cada uma das instituições. Não ocorre o contato, a aproximação, durante o processo de ECS, exceto quando o professor da IES vai até a escola para avaliar o aluno que está sob a sua supervisão. A esse respeito, Zeichner (2010) alerta que "Um problema perene em programas tradicionais de formação de professores mantidos por faculdades e universidades tem sido a da falta de conexão entre os cursos de formação de professores nessas unidades e o campo da prática" (p. 483).

Outro aspecto nevrálgico no ECS e no PIBID do IF Campo se traduz na formação e falta de tempo dos formadores para se dedicarem ao processo de orientação nestes espaços formativos. A falta de tempo pode ser atribuída às inúmeras atividades desenvolvidas, as quais envolvem o trabalho com os diferentes níveis de ensino (médio, graduação e pós-graduação), atividades de extensão e de pesquisa. Grande parte dos professores que atuam no PIBID e/ou no ECS permanecem desenvolvendo suas atividades em coordenações, direção de ensino, ou com projetos de extensão ou pesquisas aplicadas, sem vínculo com as atividades destes dois espaços formativos.

Do ponto de vista da formação, muitos dos formadores são bacharéis, com pós-graduação nas suas áreas específicas, com inexperiência em pesquisas vinculadas ao ensino e educação, bem como em práticas na educação básica. Então, a partir das fragilidades identificadas, infere-se a necessidade de maior tempo de dedicação ao PIBID e/ou ECS por parte dos formadores, de forma a participarem de processos formativos, ancorados nos princípios de uma formação reflexiva e crítica de professores, em que esses momentos são espaços de reflexão, pesquisa, intervenção e transformação. Assim, o tempo e a formação dos formadores são desafios a serem superados, para que esse processo seja de melhor qualidade, o que obrigará a que qualquer supervisor possua uma boa formação no campo da supervisão e na área específica em que os seus estagiários realizam a prática, além de ser esperado que tenha sensibilidade, abertura de olhar, facilidade de empatia, de comunicação e de relações interpessoais com os orientandos. 
Não se consegue ser bom formador de professores sem ter um conhecimento profundo sobre o campo da Formação de Professores. Ademais, atualmente são precisas novas perspectivas formativas, tendo em vista que, conforme Alarcão e Roldão (2008):

As novas tendências supervisivas apontam para uma concepção democrática de supervisão e estratégias que valorizam a reflexão, a aprendizagem em colaboração, o desenvolvimento de mecanismos de auto-supervisão e autoaprendizagem, a capacidade de gerar, gerir e partilhar o conhecimento, a assunção da escola como comunidade reflexiva e aprendente, capaz de criar para todos os que nela trabalham (incluindo os que nela estagiam) condições de desenvolvimento e de aprendizagem. (p. 19)

Assim, as novas tendências supervisivas demandam perspectivas formativas assentadas no trabalho colaborativo, na capacidade de gestão da própria aprendizagem, no desenvolvimento de práticas investigativas e reflexivas.

Em seguida, serão apresentadas as contribuições do PIBID para o ECS.

\section{Contribuições do PIBID para o ECS}

O PIBID e o ECS, além de possuírem aspectos convergentes e ambíguos, são momentos que se complementam no processo formativo de professores, na IES, na medida em que os formandos, ao ingressarem no ECS, já possuem um tempo alargado de experiência com as práticas da docência adquiridas no PIBID: "No PIBID fizemos oficinas, plano de aula, sequência didática, de organização de aula, de postura frente à sala de aula. . . . Quando fomos para o estágio já sabíamos fazer . . . aprendi no PIBID e usei no estágio" (lluminado, 20 agosto 2014).

A narrativa sinaliza a contribuição do PIBID para o ECS, tendo em vista que o tempo vivenciado na escola desde o início da formação propiciou várias oportunidades de construção da aprendizagem da docência que auxiliam os formandos, de forma significativa, no desenvolvimento das práticas do ECS. Vejamos a narrativa de outra LBP:

No PIBID ganhamos experiência ... no estágio já sabemos como funciona a escola . . . como falar com os alunos, o modo de se conseguir o respeito. ... O estágio, em si, é muito gratificante, mas com o PIBID é bem mais fácil. (Vida, 19 agosto 2014 ) 
Sobre as contribuições do PIBID para o ECS, os CA também anunciam que:

No PIBID, eles aprendem a buscar e inovar as metodologias de ensino. Percebo os alunos do PIBID aproveitando ações de intervenções realizadas na escola e aplicando no estágio. (CEM, 16 junho 2014)

O PIBID oferece mais possibilidades, explora mais, possibilita que 0 aluno vivencie situações sem estar enquadrado em caixas . . é muito flexível, diversificado, possui um cronograma nosso, mais aberto, sabe? Neste sentido, ele pode melhorar o estágio, pois pode antecipar muitas situações que o aluno verá no estágio. (CGB, 20 agosto 2014)

Por certo, a possibilidade de inserção na escola, desde o início da formação, promove aos LBP várias aprendizagens inerentes ao ofício da docência, que perpassa desde o contato com o cotidiano da escola e da sala de aula a práticas de elaboração de planejamentos, construção e aplicação de materiais didáticos, dentre outros; por conseguinte, ao realizarem o estágio, já se encontram mais preparados do que os demais licenciandos que não tiveram tal oportunidade.

\section{Considerações finais}

Com esta investigação constatou-se que o PIBID e o ECS possuem convergências, fragilidades e tensões no que se refere às suas finalidades, inserção dos formandos na escola e no processo de supervisão. Do ponto de vista das finalidades e inserção, destaca-se que estes dois momentos formativos ensejam o contato dos formandos com a realidade da escola de educação básica, seu futuro campo de trabalho, possibilitando-lhes a articulação teoria-prática, a participação em atividades reflexivas, investigativas, e a vivência de diversas situações do trabalho docente, pelas quais vão adquirir alguns dos saberes da docência.

A vivência do trabalho docente no contexto do PIBID, desde o início do curso, ensejou uma melhor preparação para a realização do ECS aos alunos que participaram do programa, evidenciando os contributos do PIBID para o ECS. Conquanto, esta é uma situação que provoca tensão e ambiguidade que se efetiva: de um lado, a proposta de melhor possibilidade na/da formação em programa que a atenda e ainda oferece bolsa para otimizar o desempenho dos participantes; e, de outro, a realidade de que a oferta é só para alguns 
devido à escassez de verbas. Se a vivência do trabalho docente, desde o início do curso, favorece uma melhor possibilidade de aprendizagem dos saberes da docência, parece ser de oportunizar a mesma aos demais licenciandos que não fazem parte do PIBID.

No que se refere ao processo supervisivo, evidenciaram-se aproximações e fragilidades entre o PIBID e o ECS. Como aproximação, destaca-se que o processo de acompanhamento nestes dois momentos formativos é semelhante, pois pressupõe ações pedagógicas a serem realizadas no cotidiano da escola sob a supervisão de um professor da IES e um professor da educação básica. Como fragilidades, identificou-se a ausência de diálogo entre os supervisores (coformador - professor da educação básica e formador - professor da IES) e a formação dos formadores. Destas fragilidades, a ausência de formação pedagógica dos formadores é elemento fulcral que fragiliza o processo supervisivo do PIBID e ECS, tendo em conta que muitos dos formadores são bacharéis, e, mesmo que possuam licenciatura na formação inicial, realizaram a pós-graduação em áreas específicas e continuam a desenvolver pesquisas nestas áreas. Esta situação incita a defesa de um processo de formação continuada, ancorado nos princípios de uma formação reflexiva e crítica de professores, em que o espaço de reflexão, pesquisa, intervenção e transformação se dê de forma híbrida, conforme salienta Zeichner (2010), no qual os professores da educação básica e da universidade se reúnam e se relacionem, de maneira menos hierárquica e mais igualitária, com vistas a promover formação qualificada aos futuros docentes.

Diante dos resultados altamente positivos, inclusive em avaliação externa (Gatti et al., 2014), que destacam a valorização da profissão docente e a mobilização das escolas, dentre outros, valida-se a experiência com o PIBID e salienta-se a necessidade de sua emergente expansão, de forma colaborativa, na IES, rede estadual e municipal de ensino. Por fim, postula-se a continuidade deste programa e o alargamento de suas práticas aos demais licenciandos dos cursos de Licenciatura, de forma a garantir a democratização do acesso de licenciandos a espaços tão ímpares, significativos e importantes de construção da identidade docente. 


\section{Notas}

1 Esta investigação foi inicialmente apresentada nos anais do ENDIPE 2016, sendo ampliada e revisada para este artigo (Paniago \& Sarmento, 2016).

2 Flávia Vieira participou de um Seminário Institucional do IF Campo em setembro de 2014.

\section{Referências}

Alarcão, I., \& Roldão, M. C.(2008). Supervisão: Um contexto de desenvolvimento profissional dos professores. Mangualde: Edições Pedago.

Alarcão, I., \& Tavares, J. (2003). Supervisão da prática pedagógica. Uma perspectiva de desenvolvimento e aprendizagem ( $2^{\mathrm{a}}$ ed.). Coimbra: Almedina.

Bardin, L. (2013). Análise de conteúdo (5 $5^{\mathrm{a}}$ ed.). Lisboa: Edições 70.

Canário, R. (2001). A prática profissional na formação de professores. In B.Campos (Org.), Formação profissional de professores no ensino superior (pp. 31-45). Porto: Porto Editora.

Clandinin, D. J., \& Connelly, F. M. (2011). Pesquisa narrativa: Experiência e história em pesquisa qualitativa. Uberlândia: EDUFU.

Gatti, B. A., \& Barretto, E. S. S. (Coords.). (2009). Professores do Brasil: Impasses e desafios. Brasília: UNESCO.

Gatti, B. A., André, M., Gimenes, N., \& Ferragut, L. (2014). Um estudo avaliativo do Programa Institucional de Bolsa de Iniciação a Docência (PIBID). São Paulo: FCC/SEP.

Gómez, A. P. (1997). O pensamento prático do professor: A formação do professor como profissional reflexivo. In A. Nóvoa (Org.), Os professores e a sua formação (3 $3^{\mathrm{a}}$ ed., pp. 93-114). Lisboa: Dom Quixote.

Ministério da Educação, Brasil (2013). Relatório de gestão DEB/CAPES. Disponível em: http://www.CAPES.gov.br/images/stories/download/bolsas/2562014-relatorioDEB-2013-web.pdf

Nascimento, M. G., Almeida, P., \& Passos, L. (2016). Formação docente e sua relação com a escola. Revista Portuguesa de Educação, 29(2), 9-34. doi:10.21814/rpe.7436

Paniago, R. N., \& Sarmento, T. (2015). O processo de estágio supervisionado na formação de professores portugueses e brasileiros. Revista Educação em Questão, 53(39), 76-103.

Paniago, R. N., \& Sarmento, T. (2016). O estágio e o PIBID: Convergências, tensões e contributos. In S. B. Monteiro (Coord.), Anais eletrônicos do XVIII Congresso Nacional de Didática e Prática de Ensino. Didática e prática de ensino no contexto político contemporâneo: Cenas da educação brasileira (pp. 21922203). Disponível em: http://www.ufmt.br/endipe2016/downloads/ Anais_Full.pdf 
Pimenta, S. G., \& Lima, M. S. L. (2011). Estágio e docência (6ª ed.). São Paulo: Cortez Editora.

Roldão, M. C. (2001). A formação como projecto: Do plano mosaico ao currículo como projecto de formação. In B. P. Campos (Org.), Formação profissional de professores no ensino superior (pp. 6-20). Porto: Porto Editora.

Sarmento, T. (2002). Histórias de vida de educadoras de infância. Lisboa: IIE.

Vieira, F. (2015, 12 dezembro). Entrevista por Rosenilde Paniago [Entrevista audiogravada]. In R. Paniago, Memorial de Pesquisa, 320p.

Vieira, F., Silva, J., Vilaça, T., Parente, C., Vieira, F., Almeida, J., ...Silva, A. (2013). O papel da investigação na prática pedagógica dos mestrados em ensino. In B. D. Silva, L. S. Almeida, A. Barca, M. Peralbo, A. Franco, \& R. Monginho (Orgs.), Atas do XII Congresso Internacional Galego-Português de Psicopedagogia (pp. 2694-2708). Braga: CIEd.

Zeichner, K. M. (2010). Repensando as conexões entre a formação na universidade e as experiências de campo na formação de professores em faculdades e universidades. Educação, 35(3), 479-504. http://periodicos. ufsm.br/ reveducacao/article/view/2357

\section{Referências legislativas}

Decreto Lei $\mathrm{n}^{\circ}$ 12.796/13, de 4 de abril. Diário Oficial [da] República Federativa do Brasil.

Portaria n 096/2013, de 18 de julho. Coordenação de Aperfeiçoamento de Pessoal de Nível Superior. Brasil.

Resolução CNE n 2/2002, de 19 de fevereiro. Resoluções CNE/CP. Brasil.

Resolução CNE n²/2015, de 1 de julho. Brasil. 


\title{
THE TEACHING PRACTICUM AND THE BRAZILIAN PROGRAM FOR BEGINNING TEACHING: CONVERGENCES, TENSIONS, AND CONTRIBUTIONS
}

\begin{abstract}
The text has its origin in research that focuses on the Institutional Program of Scientific Initiation to Teaching (PIBID), a program developed in Brazil. The goal was to analyze tensions and convergences of PIBID and Supervised Curricular Internship (SCI), as well as to identify possible contributions of PIBID for the Graduated Grant Holders of PIBID (GGH) in the SCI phase in different degrees, analyzing activities of area coordinators in this process. The theoretical axis that guides this study is teacher education, in the more specific scope of PIBID and SCI of Graduations, drawing mainly from Brazilian and Portuguese authors. A qualitative approach was adopted, materializing in a case study, supported by documental analysis and narrative interviews with nine GGHs and three area coordinators of Chemistry, Biology and Mathematics courses, from a Federal Institute of Sciences, Education and Technology. The results showed that the GGHs excelled in $\mathrm{SCl}$, indicating that this program contributes to the reflexive process of trainees. It also evidenced the approximations and weaknesses between these two formative moments in terms of their purposes, operationalization and supervision process. The results highlight some tensions, mainly resulting from the training teachers' profiles that are not always qualified to exercise the function of supervisors, which impairs their supervisory action.
\end{abstract}

Keywords

Initial Teacher Education; PIBID; Supervised Practicum

\section{LA ETAPA Y EL PROGRAMA BRASILEÑO DE INICIACIÓN A LA DOCENCIA: CONVERGENCIAS, TENSIONES Y CONTRIBUCIONES}

\section{Resumen}

El texto proviene de la investigación que se centra en el Programa Institucional de Iniciación Científica subvención a la enseñanza (PIBID), 
desarrollado en Brasil. Tuvo como objetivo analizar las tensiones y las convergencias de PIBID y Supervisado Trabajo, así como identificar las posibles contribuciones del PIBID a los becarios de grado de PIBID (LBP) en fase de Practicum supervisionado (PS) en diferentes grados, mediante el análisis de las actividades de los coordinadores de área en este proceso. La base teórica que guía este estudio es la formación de maestros, en el contexto específico de PIBID y PS de Pregrado, tomando como referencia teórica autores, especialmente brasileños y portugueses. Se adoptó la metodología del enfoque cualitativo, justo estudio de caso, basándose en el análisis de documentos y entrevistas narrativas con nueve estudiantes a maestros y tres coordinadores de área de los cursos de Química, Biología y las Matemáticas, de un Instituto Federal de Ciencia, Educación y Tecnología nombrado en la encuesta como Campo IF. Los resultados mostraron que los estudiantes a maestros se destacaran en el PS, lo que indica que este programa contribuye al proceso de reflexión de los alumnos. Si evidenció también acerca de las debilidades de estos dos tiempos de entrenamiento en relación a su propósito, operación y proceso de supervisión, que hacen hincapié en ciertas tensiones que surgen principalmente en el perfil de los formadores, que no siempre tienen la formación para el ejercicio de la función de supervisión, lo que dificulta su acción supervisiva.

Palabras-clave

Formación Inicial del Profesorado; PIBID; Prácticas Supervisadas

Recebido em novembro 2016 Aceite para publicação em setembro 2017

i Instituto Federal de Educação, Ciência e Tecnologia Goiano, Campus Rio Verde, Brasil.

ii Centro de Investigação em Estudos da Criança (CIEC), Universidade do Minho, Portugal.

iii Instituto de Ciências Humanas e Sociais, Universidade Federal de Mato Grosso, Brasil.

Toda a correspondência relativa a este artigo deve ser enviada para: Rosenilde Nogueira Paniago, Instituto Federal Goiano, Campus de Rio Verde, Goiás - Rua RC 11 lote 24, quadra 20, Residencial Canaã, Rio Verde Goiás, Brasil - Caixa Postal - n.275, Cep: 75901970. E-mail: rosenilde.paniago@ifgoiano.edu.br 